\title{
Sex differences in baroreflex function in health and disease
}

\author{
Qi Fu ${ }^{1,2} \cdot$ Shigehiko Ogoh ${ }^{3}$
}

Received: 12 July 2019 / Accepted: 29 October 2019 / Published online: 12 November 2019

(c) The Physiological Society of Japan and Springer Japan KK, part of Springer Nature 2019

\begin{abstract}
This brief review summarizes the current knowledge on sex differences in baroreflex function, with a major focus on studies in humans. It has been demonstrated that healthy women have blunted cardiovagal baroreflx sensitivity during a rapid (i.e., within seconds) hypertensive stimulus, but baroreflex sensitivity is similar between the sexes during a hypotensive stimulus. Normal aging decreases cardiovagal baroreflex sensitivity and the rate of decline is similar in men and women. Cardiovagal baroreflex sensitivity is reduced in pathological conditions such as hypertension and type II diabetes, and the reduction is greater in female patients than male patients. There is no clear sex difference in sympathetic baroreflex sensitivity among young individuals, however, with women of more advanced age, sympathetic baroreflex sensitivity decreases, which appears to be associated with greater arterial stiffness compared with similarly aged men. The blunted sympathetic baroreflex sensitivity in older women may predispose them to an increased prevalence of hypertension and cardiovascular disease.
\end{abstract}

Keywords Cardiovagal baroreflex sensitivity $\cdot$ Sympathetic baroreflex sensitivity $\cdot$ Blood pressure $\cdot$ Hypotension . Hypertension

\section{Introduction}

There are physical and physiological sex differences in humans. For instance, on average, men are bigger and more muscular than women. In addition, men and women have different circulating levels of the sex hormone testosterone and estrogen. Compared to men, women demonstrate more profound changes in sex hormone status, body composition and neural-vascular profiles with normal aging due to menopause (loss of estrogen) in mid-life. These sex-specific differences may impact baroreflex function in health and disease (i.e., hypertension, heart failure, type II diabetes, etc.).

Indeed, epidemiological studies have suggested that impaired baroreflex function is one of the predictors of

Qi Fu

QiFu@TexasHealth.org

1 Women's Heart Health Laboratory, Institute for Exercise and Environmental Medicine, Texas Health Presbyterian Hospital Dallas, 7232 Greenville Avenue, Suite 435, Dallas, TX 75231, USA

2 The University of Texas Southwestern Medical Center, Dallas, TX, USA

3 Department of Biomedical Engineering, Toyo University, Tokyo, Japan cardiovascular events and all-cause morbidity and mortality [6-8]. An increase in the prevalence of hypertension and cardiovascular disease with aging is higher in women than men $[9,10]$, which may be attributed, in part, to sex-specific differences in baroreflex function. Despite its clinical importance, how sex affects the baroreflex in the young and the old, during exercise, and in pathology has not been reviewed systematically.

The baroreflex, which includes the cardiovagal (cardiac control) and sympathetic (vasculature control) components (Fig. 1), plays an important role in both short-term and longterm regulation of blood pressure in humans [1-3]. Importantly, alterations in these baroreflex functions are associated with physiological factors including aging and sex or pathological conditions. In this review, the cardiovagal baroreflex refers to the relationship between heart rate or $R-R$ interval and blood pressure [4]. Also, the sympathetic baroreflex refers to the relationship between vasomotor sympathetic outflow, which can be recorded by the microneurographic technique as muscle sympathetic nerve activity (MSNA) [5], and blood pressure [4]. The purpose of this brief review is to systematically summarize the current knowledge on sex differences in baroreflex function, with the main focus on studies in humans. 


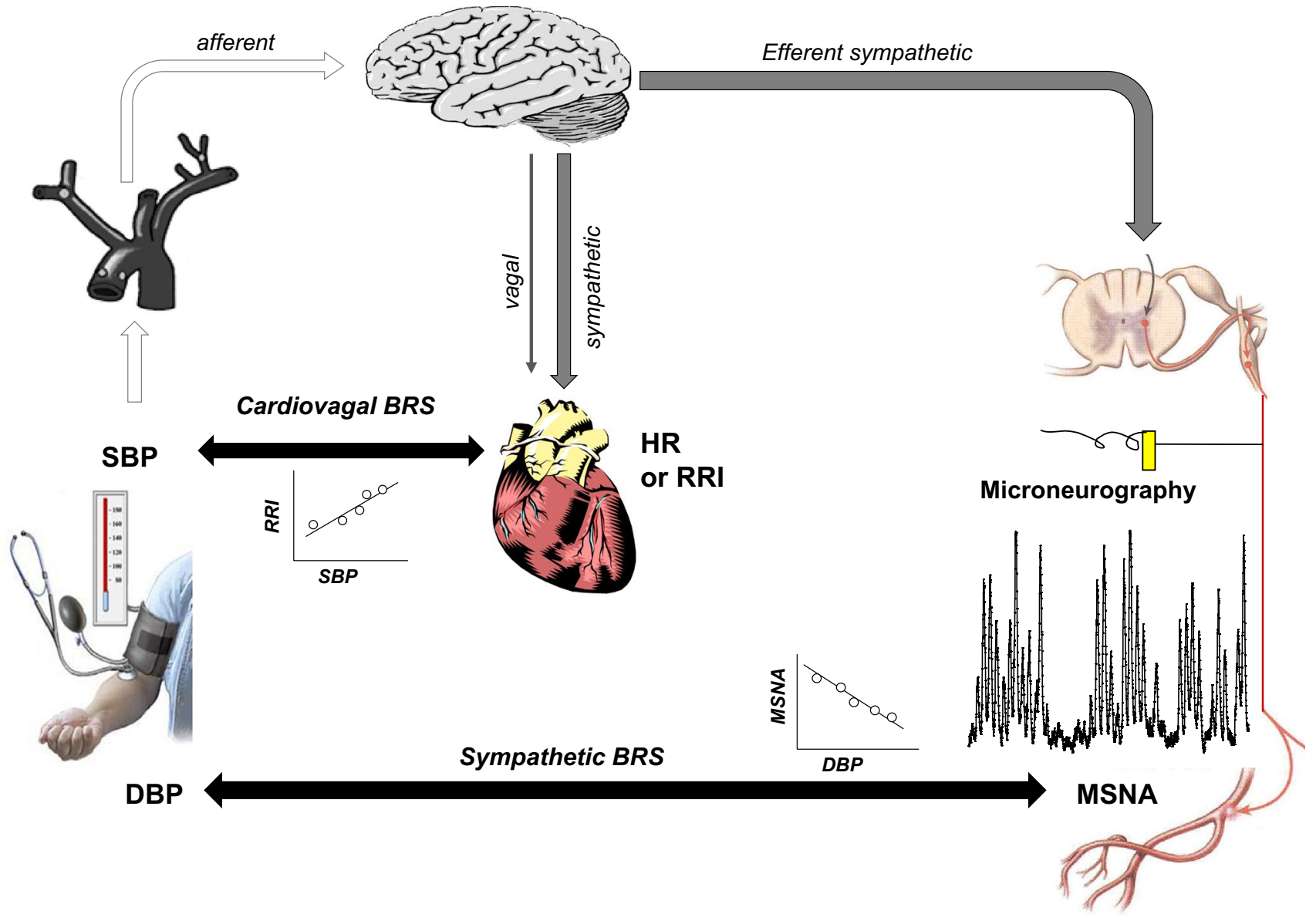

Fig. 1 Illustration of the cardiovagal and sympathetic baroreflex. $B R S$ baroreflex sensitivity, $D B P$ diastolic blood pressure, $H R$ heart rate, $M S N A$ muscle sympathetic nerve activity, RRI R-R interval, SBP systolic blood pressure

\section{Cardiovagal baroreflex function}

\section{Sex differences in baroreflex sensitivity among young individuals}

The first study on sex differences in cardiovagal baroreflex sensitivity was published in the early 1990s. AbdelRahman et al. [11] found that the slope of the line relating changes in heart rate and mean arterial pressure was much steeper in healthy young men compared with young women when blood pressure was rapidly (i.e., within seconds) increased by an intravenous bolus injection of phenylephrine. These results suggest that the response of the cardiovagal baroreflex to acute hypertension is substantially greater in young men than in young women. Similarly, using the modified Oxford method (rapid hypo and hypertensive stimulations by intravenous bolus injections of nitroprusside and phenylephrine, respectively), it was confirmed that cardiovagal baroreflex sensitivity was greater in healthy young men compared with young women despite no sex differences in other characteristics of the baroreflex function curve (e.g., the threshold, saturation, operating range, and operating point, Fig. 2) [12]. However, Tank et al. [13] reported that during incremental phenylephrine and nitroprusside infusions [slowly (i.e., within minutes) increasing and then decreasing blood pressure], cardiovagal baroreflex sensitivity was similar between the sexes. Collectively, these studies indicate that the rate of blood pressure change (e.g., rapidly or slowly) can impact cardiovagal baroreflex sensitivity differently in young men versus young women. On the other hand, a recent report showed that cardiovagal baroreflex sensitivity to natural blood pressure variation around the operating point identified by transfer function analysis of the lowfrequency region $(0.04-0.15 \mathrm{~Hz})$ between $R-R$ interval and mean arterial pressure was smaller rather than greater in healthy young men compared with young women [14]. These observations need to be confirmed in future studies.

Similarly, we also found that cardiovagal baroreflex sensitivity was not significantly different between young men and young women when blood pressure was rapidly decreased; 


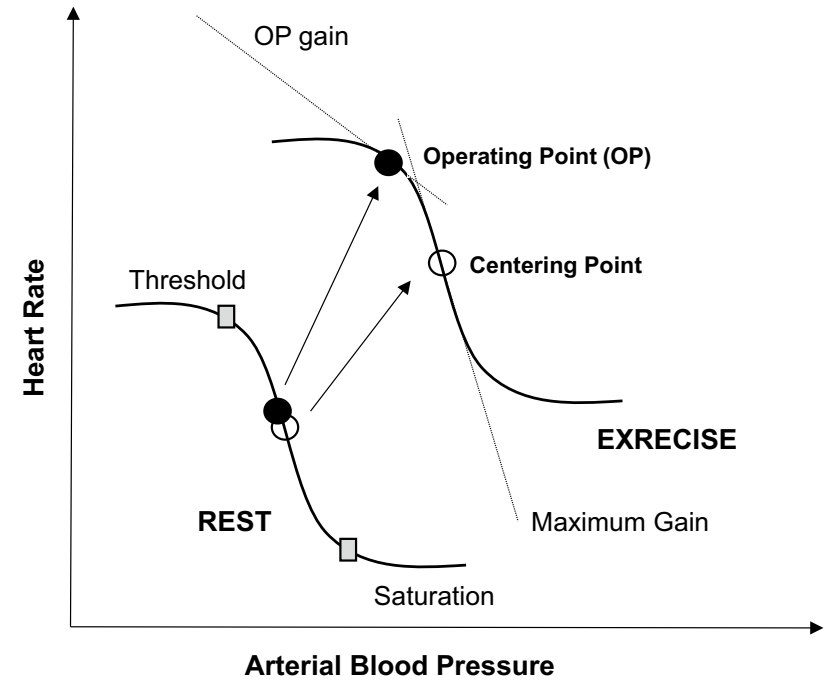

Fig. 2 Hypothetical cardiovagal baroreflex curve at rest and during exercise expressed as the relationship between heart rate and arterial blood pressure. Resetting of the baroreflex occurs from rest to exercise. OP, operating point however, baroreflex sensitivity was greater in men compared with women when blood pressure was rapidly increased (Fig. 3) [4]. Observations from the previous studies with experimental animals have shown that baroreflex-mediated bradycardia during acute hypertension involves reciprocal changes in vagal activation and sympathetic activity inhibition [15]. Sex dimorphism in cardiovagal baroreflex sensitivity has been proposed, at least in part, to be associated with different autonomic cardiac control in males and females. An increase in vagal tone occurs rapidly, whereas sympathetic withdrawal happens more slowly $[15,16]$, indicating that baroreflex control of heart rate is mainly regulated by vagal outflow during a rapid change in blood pressure. Indeed, it was reported that an increase in vagal outflow to the heart in response to baroreceptor activation (loading) was smaller in females compared with males [17].

One unique feature in young (premenopausal) women is fluctuations of the female sex hormone estrogen and progesterone during the normal menstrual cycle. Using the modified Oxford method, Minson et al. [18] found that cardiovagal baroreflex sensitivity was similar between the
A
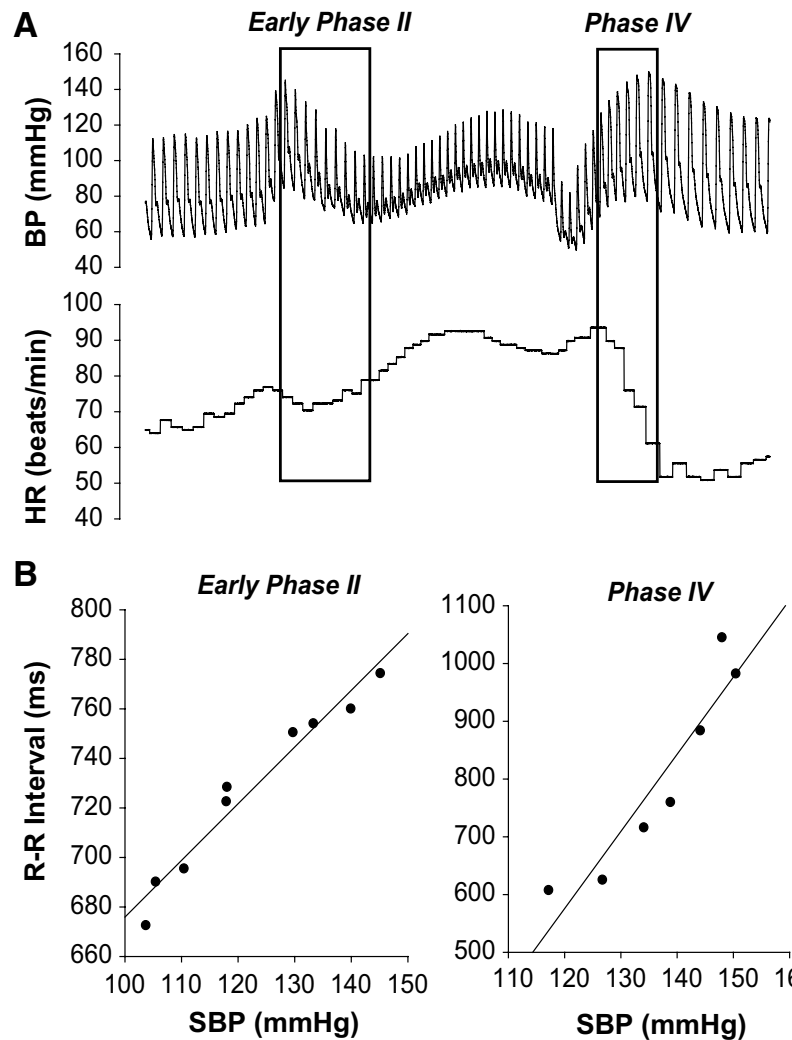

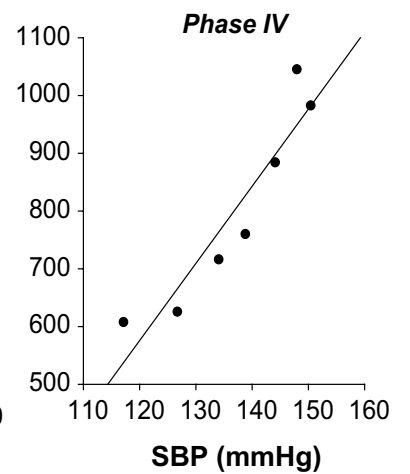

C
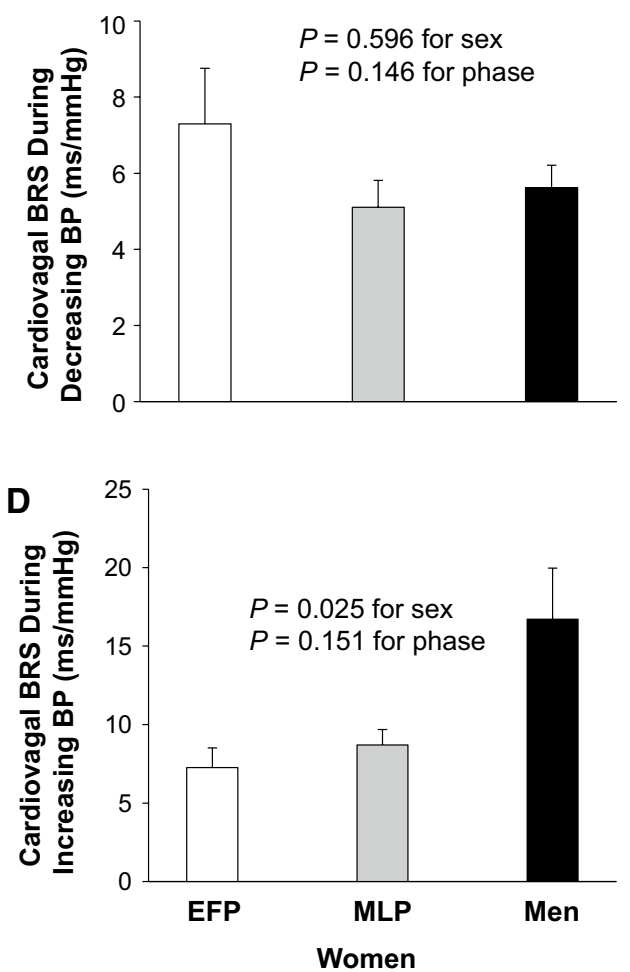

Fig. 3 Effects of sex and the menstrual cycle on cardiovagal barorefex sensitivity in healthy young individuals. a cardiovagal BRS assessed during early phase II and phase IV of the Valsalva maneuver. b The slope of the linear relationship between R-R interval and SBP indicates cardiovagal BRS. c The sensitivity during decreasing $\mathrm{BP}$ was not different between the sexes and menstrual phases in women. d However, it was greater in men than women of both phases during increasing BP. Values are mean \pm SE. BRS baroreflex sensitivity, $B P$ blood pressure, $E F P$ the early follicular phase, $H R$ heart rate, $M L P$ the mid-luteal phase, $S B P$ systolic blood pressure. Reproduced with permission from Fu et al. [4] 
early follicular phase (e.g., 1-5 days after the onset of menstruation when both estrogen and progesterone are low) and the mid-luteal phase (e.g., 19-22 days after the onset of menstruation when both hormones are high) in healthy premenopausal women. Our study [4] confirmed the findings of Minson et al. using a different technique that evaluates cardiovagal baroreflex sensitivity-a Valsalva maneuver which includes a hypotensive stimulus in early phase II and a hypertensive stimulus in phase IV. These studies suggest that cyclic changes in estrogen and progesterone during the normal menstrual cycle have no significant impact on cardiovagal baroreflex sensitivity in healthy young women. It is possible that these two hormones may have counteractive effects on the cardiovagal baroreflex.

\section{Baroreflex resetting during exercise in young men and women}

Both heart rate and blood pressure increase during exercise and the baroreflex resets to a higher pressure level [19-23]. The baroreflex curve is shifted to the right and upward from rest to exercise. Moreover, the operating point is also shifted to the right-upward which is away from the centering point and towards the threshold on the functional curve, and thus, at a locus of reduced gain (Fig. 2) [24]. It is believed that central command resets the baroreflex to the higher pressure level so that heart rate, and thus, cardiac output increase by the sudden withdrawal of vagal outflow to the heart to meet the metabolic demand during exercise [21]. In addition, activation of the exercise pressor reflex may also contribute to the resetting of the baroreflex [19-23]. Previous studies in humans and animals have suggested that both sex and sex hormones may modify central command and the exercise pressor reflex [25-30], and young women demonstrate attenuated metaboreflex activation compared with young men [25, 31]. Therefore, it would be expected that the differences in central command and exercise pressure reflex between men and women modify the resetting of baroreflex function during exercise. In contrast to this speculation, the magnitude of resetting of the baroreflex during exercise was not different between the sexes [32]. Likewise, there was a right-upward resetting of the baroreflex curve from rest to exercise in both sexes, but baroreflex sensitivity at the operating point during exercise was smaller in men compared with women during exercise [32]. These findings suggest that baroreflex sensitivity was modified by sex and/or sex hormones during exercise despite no significant difference in the resetting of baroreflex between men and women.

The impact of the menstrual cycle on baroreflex function in healthy premenopausal women during leg cycling exercise was also investigated in previous studies [32]. Subjects were evaluated three times: (1) during the early follicular phase when both estrogen and progesterone levels are low; (2) the late follicular phase when estrogen is high but progesterone is low; and (3) the mid-luteal phase when both sex hormone levels are high. It was found that menstrual cycle phases did not affect the maximal baroreflex sensitivity (gain) as well as the gain at the operating point in young women. However, augmented pressor responses to acute hypotension were observed in young women during the mid-luteal phase compared with the early- and late-follicular phase. Nevertheless, the effect of the menstrual cycle on the resetting of baroreflex function during exercise remains largely to be elucidated.

\section{Age and sex dependency of cardiovagal baroreflex sensitivity}

Physiological factors, particularly age and sex have significant influences on cardiovagal baroreflex function in humans. Advancing age decreases baroreflex sensitivity even in the healthy population [33-36]. Previous investigations showed that the relative rate of decline in cardiovagal baroreflex sensitivity with normal aging was similar between the sexes despite a greater baroreflex sensitivity in men compared with women (Fig. 4) [37]. Similar to our prior work in the healthy young population [4], we also found that cardiovagal baroreflex sensitivity was greater in older men compared with older women during acute (rapid) hypertension, but it was not different between the sexes during acute hypotension [38]. In both men and women, cardiovagal baroreflex sensitivity was found to be negatively correlated with diastolic or systolic blood pressure in young or middleaged and older individuals, respectively [37]. On the other hand, cardiovagal baroreflex sensitivity was positively correlated with peak oxygen uptake (an indication of physical fitness) and high-frequency power of heart rate variability (an indication of cardiovagal activity) in all individuals [37]. Of note, the positive correlation between baroreflex sensitivity and physical fitness reported by Laitinen et al. [35] could have been confounded by aging per se, as both young and older individuals were included in the analysis. However, previous longitudinal studies demonstrated that endurance exercise training increased both peak oxygen uptake and cardiovagal baroreflex sensitivity in healthy young individuals [39]. These results indicate a potential link between physical fitness and baroreflex sensitivity independent of age.

The mechanisms underlying age- and sex-specific differences in cardiovagal baroreflex sensitivity may be multifactorial. Numerous studies have shown that aging is associated with increased arterial stiffness in humans, especially in women and as a result, the stimulation of baroreceptors is decreased (arterial stiffness-induced decrease in the distortion of baroreceptors), which leads to a lower cardiovagal baroreflex sensitivity in older women than older men [37]. It is also possible that normal aging reduces baroreflex 
Fig. 4 Relationship between cardiovagal baroreflex sensitivity and age in men (a) and in women (b). Regression slopes and $95 \%$ confidence intervals are shown. BRS baroreflex sensitivity. Reproduced with permission from Laitinen et al. [37]

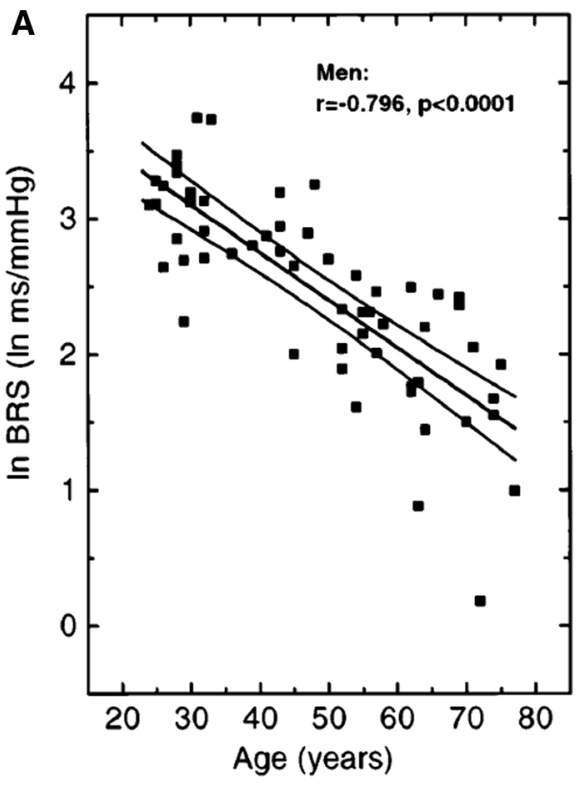

sensitivity through changes in peripheral afferent and/or efferent pathways, central neural control of the baroreflex system, and sinus node function [37], while these changes may be more dramatic in women compared with men. Additionally, changes in autonomic function with age (e.g., increased sympathetic activity and decreased vagal tone, especially in older women) may also contribute to the sexspecific reduction in cardiovagal baroreflex sensitivity with aging. Huikuri et al. [40] previously found that baroreflex sensitivity was greater in postmenopausal women taking hormonal replacement therapy than in those who did not. These results suggest that sex hormones, in particular, estrogen may play a role in the age-related decrease in cardiovagal baroreflex sensitivity in older women. Interestingly, in premenopausal women, fluctuations of female sex hormones during the menstrual cycle do not impact cardiovagal baroreflex sensitivity $[4,18]$. The discrepancy between young and old women may be explained, in part, by differences in the source of hormones, namely, endogenous versus exogenous estrogen.

\section{Sex differences in baroreflex sensitivity in hypertension and type 2 diabetes}

The evidence that human hypertension is associated with impairment of cardiovagal baroreflex function is strong. Both systolic and diastolic blood pressure were found to be correlated significantly with cardiovagal baroreflex sensitivity [37]. Increased arterial stiffness, augmented sympathetic activity and decreased vagal tone may be responsible for the reduction in cardiovagal baroreflex sensitivity in patients with hypertension [41-45]. There is also evidence showing that impaired baroreflex function is not only a consequence of hypertension but also may contribute to the development of hypertension [44-46]. For instance, it was found in patients with essential hypertension, of all variables investigated, family history of hypertension was the strongest unique baroreflex sensitivity predictor [46]. These results suggest that the impairment in cardiovagal baroreflex sensitivity in hypertension may be an important hereditary component in the pathogenesis of essential hypertension. Consistent with these previous observations [46], recent research showed that healthy young women with a positive family history of hypertension had reduced cardiovagal baroreflex sensitivity determined by the Valsalva maneuver (phase IV) when blood pressure was rapidly increased [47]. This may be one possible mechanism for the increased risk of hypertension in people who have a positive family history.

In middle-aged patients with uncontrolled or un-medicated hypertension (mean age about 50 years old), cardiovagal baroreflex sensitivity was reduced and the magnitude of reduction was significantly greater in female patients than in male patients [48]. Whether this is also true in older patients with hypertension remains to be determined. This is a clinically important issue to address because an increase in the prevalence and morbidity rate of hypertension with aging is higher in women than men $[9,10]$. Furthermore, a depressed cardiovagal baroreflex sensitivity predicts cardiovascular events, particularly in female patients [49].

Research in the Japanese population demonstrated that female patients with type 2 diabetes had lower cardiovagal baroreflex sensitivity compared to male patients [49]. This finding may explain, at least in part, why diabetic women have a significantly greater rate of ischemic heart disease mortality than diabetic men $[50,51]$. Taken together, these studies suggest that type II diabetes, hypertension, and 
cardiovascular disease attenuate cardiovagal baroreflex sensitivity differently in men versus women, though the underlying mechanisms remain unknown.

\section{Sympathetic baroreflex function}

\section{Sympathetic baroreflex sensitivity in healthy young men and women}

Tank et al. [13] previously reported that the baroreflex curve was shifted toward lower systolic blood pressure values in young women (indicating a resetting of the sympathetic baroreflex), and at given systolic blood pressure, MSNA tended to be lower in women than in similarly aged men. However, there was no difference in sympathetic baroreflex sensitivity between the sexes $[13,52]$. Consistent with these observations, we also found that sympathetic baroreflex sensitivity was similar in healthy young men and women [4]. In our study, we used diastolic pressure rather than systolic pressure as an input stimulus or an independent variable for MSNA, since it has been demonstrated that when, for each cardiac cycle, the occurrence of a sympathetic burst is correlated with different blood pressure parameters there is regularly a close negative correlation to diastolic pressure, a low correlation to systolic, and an intermediary negative correlation to mean arterial pressure [53].

We also found that baroreflex sensitivity assessed by the Valsalva maneuver (Fig. 5), as well as with the spontaneous breathing method was not significantly different between the early follicular phase and the mid-luteal phase in young women [4]. These results are inconsistent with the study by Minson et al. [18], showing that sympathetic baroreflex sensitivity measured by the modified Oxford method was greater in the mid-luteal phase than the early follicular phase in young women. The discrepancies between these studies may be attributed to the different methods used to evaluate sympathetic baroreflex sensitivity (i.e., pharmacologic versus non-pharmacologic approach) and/or variable surges in estrogen and progesterone (i.e., the ratio of the change in estrogen relative to the change in progesterone at different time point during the menstrual cycle) [54]. On the other hand, in response to orthostatic challenges, sympathetic baroreflex sensitivity was found to increase in all individuals and the increment was similar between healthy young men and women during different menstrual phases $[4,55]$.

\section{Age and sex dependency of sympathetic baroreflex sensitivity}

The sympathetic baroreflex contains mechanical and neural components, and all together is considered integrated baroreflex [38]. Studinger et al. [56] reported that normal
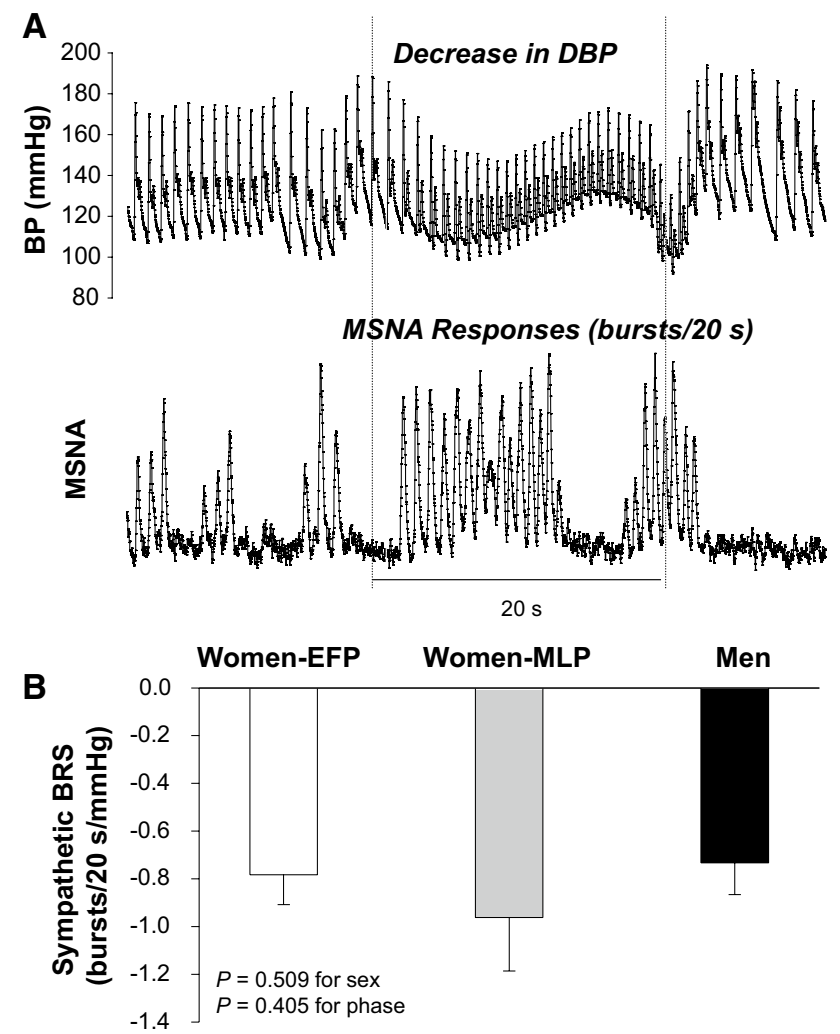

Fig. 5 Effects of sex and the menstrual cycle on sympathetic baroreflex sensitivity in healthy young individuals. a Sympathetic BRS assessed during the Valsalva maneuver. b The sensitivity was not different between the sexes and menstrual phases. Values are mean $\pm \mathrm{SE}$. $B R S$ baroreflex sensitivity, EFP the early follicular phase, MLP the mid-luteal phase. Reproduced with permission from Fu et al. [4]

aging reduced mechanical component of sympathetic baroreflex sensitivity but did not change neural component and integrated baroreflex. These findings imply the possibility that aging may cause impairment in sympathetic baroreflex function. Indeed, it was found that sympathetic baroreflex sensitivity during falling blood pressure decreased with age despite no change during increasing blood pressure [50]. In contrast, previous research showed that sympathetic baroreflex sensitivity remained unchanged with advancing age in healthy individuals, although the line relating MSNA and diastolic blood pressure was shifted in parallel to the right (resetting) and the operating point of the baroreflex curve was shifted to the right-upward with age [34]. Therefore, the effect of aging on sympathetic baroreflex sensitivity remains controversial.

Among healthy older individuals, sympathetic baroreflex sensitivity was reported to be similar between the sexes $[56,57]$. However, we found that older women had lower sympathetic baroreflex sensitivity compared with older men (Fig. 6) [38]. One main reason behind these contradictory findings is the age difference; participants in our 
Fig. 6 Sympathetic baroreflex sensitivity calculated from burst incidence (a) and total muscle sympathetic nerve activity (MSNA; b) during spontaneous breathing in the supine position in older men and older women. Values are mean \pm SE. BRS baroreflex sensitivity Adapted and reproduced with permission from Okada et al. [38]

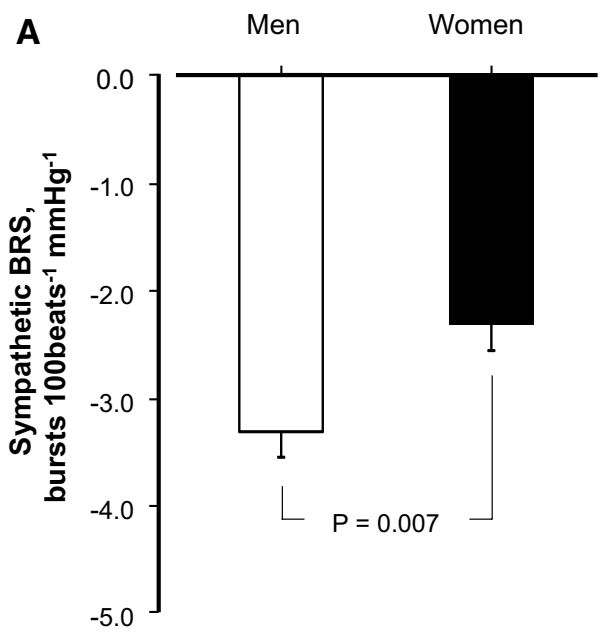

study were 10 years older than those in previous studies (i.e., mean age about 70 versus 60 years old) $[56,57]$. We also found that sympathetic baroreflex sensitivity was correlated with $\beta$-stiffness of carotid artery but not aorta in both sexes, while older women had greater carotid and aortic stiffness compared with older men [38]. The blunted sympathetic baroreflex sensitivity in older women may predispose them to an increased prevalence of hypertension and cardiovascular disease.

\section{Sympathetic baroreflex sensitivity in hypertension and cardiovascular disease}

Blunted sympathetic baroreflex sensitivity is linked with many pathological conditions. For instance, it was found that patients with hypertension, especially those with resistant hypertension had significantly lower sympathetic baroreflex sensitivity compared with age-matched healthy normotensive individuals [58]. In addition, recent studies showed that heart failure with preserved, midrange and reduced ejection fraction was associated with marked sympathetic overactivity, which was attributed to baroreflex dysfunction and decreased baroreflex sensitivity [59]. On the other hand, baroreflex activation therapy by implanting a small device to electrically stimulate baroreceptors in the carotid sinus region was reported not only to improve hemodynamic and clinical profile but also to exert profound sympathoinhibitory effects in patients with heart failure, allowing an almost complete restoration of physiological levels of the sympathetic neural function [60]. Despite the fact that the prevalence of hypertension and cardiovascular disease is greater in women than in men as they age $[9,10]$, sex-specific differences in sympathetic baroreflex function in pathological conditions have never been investigated in previous studies. It is not known whether the magnitude of reduction in sympathetic baroreflex sensitivity is similar or different in male and female patients with hypertension and cardiovascular disease.

\section{Conclusions}

Compared to men, women have lower cardiovagal baroreflx sensitivity during a rapid hypertensive (but not hypotensive) stimulus, which may be attributed to sex differences in vagal activation to the heart in response to baroreceptor loading. Cardiovagal baroreflex sensitivity decreases with age presumably due to increased largeartery (barosensory) stiffness, as well as changes in afferent/efferent pathways, central neural control, and sinus node function; the rate of decline is similar between the sexes. Reduced cardiovagal baroreflex sensitivity is linked to hypertension and type II diabetes, whereas the magnitude of reduction in sensitivity is greater in female than male patients. Although sympathetic baroreflex sensitivity is similar between healthy young men and women, it is lower in older women compared to older men. Blunted sympathetic baroreflex sensitivity is associated with hypertension and cardiovascular disease. However, whether sex differences exist in sympathetic baroreflex sensitivity in pathology needs to be determined.

Acknowledgements This brief review article was supported, in part, by the National Institutes of Health grants K23 (HL075283), R21 (HL088184) and R01 (HL091078), and the American Heart Association Grant-in-Aid Grant award (16GRNT27760130).

\section{Compliance with ethical standards}

Conflict of interest There is no conflict of interest to disclose. 


\section{References}

1. Fu Q, Shook RP, Okazaki K, Hastings JL, Shibata S, Conner CL, Palmer MD, Levine BD (2006) Vasomotor sympathetic neural control is maintained during sustained upright posture in humans. J Physiol 577:679-687

2. Head GA, Saigusa T, Mayorov DN (2002) Angiotensin and baroreflex control of the circulation. Braz J Med Biol Res 35:1047-1059

3. Lohmeier TE (2001) The sympathetic nervous system and longterm blood pressure regulation. Am J Hypertens 14:147s-154s

4. Fu Q, Okazaki K, Shibata S, Shook RP, Vangunday TB, Galbreath MM, Reelick MF, Levine BD (2009) Menstrual cycle effects on sympathetic neural responses to upright tilt. J Physiol 587:2019-2031

5. Vallbo AB, Hagbarth KE, Wallin BG (2004) Microneurography: how the technique developed and its role in the investigation of the sympathetic nervous system. J Appl Physiol (1985) 96:1262-1269

6. Billman GE, Schwartz PJ, Stone HL (1982) Baroreceptor reflex control of heart rate: a predictor of sudden cardiac death. Circulation 66:874-880

7. La Rovere MT, Pinna GD, Hohnloser SH, Marcus FI, Mortara A, Nohara R, Bigger JT, Camm AJ, Schwartz PJ (2001) Baroreflex sensitivity and heart rate variability in the identification of patients at risk for life-threatening arrhythmias: implications for clinical trials. Circulation 103:2072-2077

8. Burt VL, Whelton P, Roccella EJ, Brown C, Cutler JA, Higgins M, Horan MJ, Labarthe D (1995) Prevalence of hypertension in the us adult population. Results from the third national health and nutrition examination survey, 1988-1991. Hypertension 25:305-313

9. Gudmundsdottir H, Hoieggen A, Stenehjem A, Waldum B, Os I (2012) Hypertension in women: latest findings and clinical implications. Ther Adv Chronic Dis 3:137-146

10. Navin Cristina TJ, Stewart Williams JA, Parkinson L, Sibbritt DW, Byles JE (2016) Identification of diabetes, heart disease, hypertension and stroke in mid- and older-aged women: comparing self-report and administrative hospital data records. Geriatr Gerontol Int 16:95-102

11. Abdel-Rahman AR, Merrill RH, Wooles Wr (1994) Genderrelated differences in the baroreceptor reflex control of heart rate in normotensive humans. J Appl Physiol (1985) 77:606-613

12. Beske SD, Alvarez GE, Ballard TP, Davy KP (2001) Gender difference in cardiovagal baroreflex gain in humans. J Appl Physiol (1985) 91:2088-2092

13. Tank J, Diedrich A, Szczech E, Luft FC, Jordan J (2005) Baroreflex regulation of heart rate and sympathetic vasomotor tone in women and men. Hypertension 45:1159-1164

14. Klassen SA, Chirico D, Dempster KS, Shoemaker JK, O’leary DD (2016) Role of aortic arch vascular mechanics in cardiovagal baroreflex sensitivity. Am J Physiol Regul Integr Comp Physiol 311:R24-R32

15. Coleman TG (1980) Arterial baroreflex control of heart rate in the conscious rat. Am J Physiol 238:H515-H520

16. Katona PG, Poitras JW, Barnett GO, Terry BS (1970) Cardiac vagal efferent activity and heart period in the carotid sinus reflex. Am J Physiol 218:1030-1037

17. Abdel-Rahman AA (1999) Gender difference in baroreflexmediated bradycardia in young rats: role of cardiac sympathetic and parasympathetic components. Can J Physiol Pharmacol 77:358-366

18. Minson CT, Halliwill JR, Young TM, Joyner MJ (2000) Influence of the menstrual cycle on sympathetic activity, baroreflex sensitivity, and vascular transduction in young women. Circulation 101:862-868
19. Raven PB, Potts JT, Shi X (1997) Baroreflex regulation of blood pressure during dynamic exercise. Exerc Sport Sci Rev 25:365-389

20. Ogoh S, Fisher JP, Raven PB, Fadel PJ (2007) Arterial baroreflex control of muscle sympathetic nerve activity in the transition from rest to steady-state dynamic exercise in humans. Am J Physiol Heart Circ Physiol 293:H2202-H2209

21. Ogoh S, Wasmund WL, Keller DM, Gallagher KM, Mitchell JH, Raven PB (2002) Role of central command in carotid baroreflex resetting in humans during static exercise. J Physiol 543:349-364

22. Raven PB (2008) Recent advances in baroreflex control of blood pressure during exercise in humans: an overview. Med Sci Sports Exerc 40:2033-2036

23. Raven PB, Fadel PJ, Ogoh S (2006) Arterial baroreflex resetting during exercise: a current perspective. Exp Physiol 91:37-49

24. Raven PB, Fadel PJ, Smith SA (2002) The influence of central command on baroreflex resetting during exercise. Exerc Sport Sci Rev 30:39-44

25. Ettinger SM, Silber DH, Collins BG, Gray KS, Sutliff G, Whisler SK, Mcclain JM, Smith MB, Yang QX, Sinoway LI (1996) Influences of gender on sympathetic nerve responses to static exercise. J Appl Physiol (1985) 80:245-251

26. Ettinger SM, Silber DH, Gray KS, Smith MB, Yang QX, Kunselman AR, Sinoway LI (1998) Effects of the ovarian cycle on sympathetic neural outflow during static exercise. J Appl Physiol (1985) 85:2075-2081

27. Hayes SG, Del Pino Moya NB, Kaufman MP (2002) Estrogen attenuates the cardiovascular and ventilatory responses to central command in cats. J Appl Physiol 92:1635-1641

28. Schmitt PM, Kaufman MP (2005) Estrogen's attenuating effect on the exercise pressor reflex is more opioid dependent in gonadally intact than in ovariectomized female cats. J Appl Physiol (1985) 98:633-639

29. Schmitt PM, Kaufman MP (2003) Estrogen attenuates the exercise pressor reflex in female cats. J Appl Physiol (1985) 95:1418-1424

30. Schmitt PM, Kaufman MP (2003) High concentrations of 17betaestradiol attenuate the exercise pressor reflex in male cats. J Appl Physiol (1985) 94:1431-1436

31. Jarvis SS, Vangundy TB, Galbreath MM, Shibata S, Okazaki K, Reelick MF, Levine BD, Fu Q (2011) Sex differences in the modulation of vasomotor sympathetic outflow during static handgrip exercise in healthy young humans. Am J Physiol Regul Integr Comp Physiol 301:R193-R200

32. Kim A, Deo SH, Fisher JP, Fadel PJ (2012) Effect of sex and ovarian hormones on carotid baroreflex resetting and function during dynamic exercise in humans. J Appl Physiol (1985) 112:1361-1371

33. Duke PC, Wade JG, Hickey RF, Larson CP (1976) The effects of age on baroreceptor reflex function in man. Can Anaesth Soc J 23:111-124

34. Ebert TJ, Morgan BJ, Barney JA, Denahan T, Smith JJ (1992) Effects of aging on baroreflex regulation of sympathetic activity in humans. Am J Physiol 263:H798-H803

35. Gribbin B, Pickering TG, Sleight P, Peto R (1971) Effect of age and high blood pressure on baroreflex sensitivity in man. Circ Res 29:424-431

36. Shimada K, Kitazumi T, Sadakane N, Ogura H, Ozawa T (1985) Age-related changes of baroreflex function, plasma norepinephrine, and blood pressure. Hypertension 7:113-117

37. Laitinen T, Hartikainen J, Vanninen E, Niskanen L, Geelen G, Lansimies E (1998) Age and gender dependency of baroreflex sensitivity in healthy subjects. J Appl Physiol (1985) 84:576-583

38. Okada Y, Galbreath MM, Shibata S, Jarvis SS, Vangundy TB, Meier RL, Vongpatanasin W, Levine BD, Fu Q (2012) Relationship between sympathetic baroreflex sensitivity and arterial stiffness in elderly men and women. Hypertension 59:98-104 
39. Cooke WH, Reynolds BV, Yandl MG, Carter JR, Tahvanainen KU, Kuusela TA (2002) Effects of exercise training on cardiovagal and sympathetic responses to valsalva's maneuver. Med Sci Sports Exerc 34:928-935

40. Huikuri HV, Pikkujamsa SM, Airaksinen KE, Ikaheimo MJ, Rantala AO, Kauma H, Lilja M, Kesaniemi YA (1996) Sex-related differences in autonomic modulation of heart rate in middle-aged subjects. Circulation 94:122-125

41. Kingwell BA, Cameron JD, Gillies KJ, Jennings GL, Dart AM (1995) Arterial compliance may influence baroreflex function in athletes and hypertensives. Am J Physiol 268:H411-H418

42. Lage SG, Polak JF, O'leary DH, Creager MA (1993) Relationship of arterial compliance to baroreflex function in hypertensive patients. Am J Physiol 265:H232-H237

43. Randall O, Esler M, Culp B, Julius S, Zweifler A (1978) Determinants of baroreflex sensitivity in man. J Lab Clin Med 91:514-519

44. Matsukawa T, Gotoh E, Hasegawa O, Shionoiri H, Tochikubo O, Ishii M (1991) Reduced baroreflex changes in muscle sympathetic nerve activity during blood pressure elevation in essential hypertension. J Hypertens 9:537-542

45. Yamada Y, Miyajima E, Tochikubo O, Matsukawa T, Shionoiri H, Ishii M, Kaneko Y (1988) Impaired baroreflex changes in muscle sympathetic nerve activity in adolescents who have a family history of essential hypertension. J Hypertens Suppl 6:S525-S528

46. Parmer RJ, Cervenka JH, Stone RA (1992) Baroreflex sensitivity and heredity in essential hypertension. Circulation 85:497-503

47. El Matthews, Kn Sebzda, Mm Wenner (2019) Altered Baroreflex Sensitivity In Young Women With A Family History Of Hypertension. J Neurophysiol 121:1011-1017

48. Sevre K, Lefrandt JD, Nordby G, Os I, Mulder M, Gans RO, Rostrup M, Smit AJ (2001) Autonomic function in hypertensive and normotensive subjects: the importance of gender. Hypertension 37:1351-1356

49. Yufu K, Takahashi N, Okada N, Wakisaka O, Shinohara T, Nakagawa M, Hara M, Yoshimatsu H, Saikawa T (2011) gender difference in baroreflex sensitivity to predict cardiac and cerebrovascular events in type 2 diabetic patients. Circ J 75:1418-1423

50. Kanaya AM, Grady D, Barrett-Connor E (2002) Explaining the sex difference in coronary heart disease mortality among patients with type 2 diabetes mellitus: a meta-analysis. Arch Intern Med 162:1737-1745

51. Barrett-Connor EL, Cohn BA, Wingard DL, Edelstein SL (1991) Why is diabetes mellitus a stronger risk factor for fatal ischemic heart disease in women than in men? The rancho bernardo study. JAMA 265:627-631

52. Ec Hart, Charkoudian N (2011) Sympathetic Neural Mechanisms In Human Blood Pressure Regulation. Curr Hypertens Rep $13: 237-243$

53. Sundlof G, Wallin BG (1978) Human muscle nerve sympathetic activity at rest. relationship to blood pressure and age. J Physiol 274:621-637

54. Carter JR, Fu Q, Minson CT, Joyner MJ (2013) Ovarian cycle and sympathoexcitation in premenopausal women. Hypertension 61:395-399

55. Carter JR, Lawrence JE, Klein JC (2009) menstrual cycle alters sympathetic neural responses to orthostatic stress in young, eumenorrheic women. Am J Physiol Endocrinol Metab 297:E85-E91

56. Studinger P, Goldstein R, Taylor JA (2009) Age- and fitnessrelated alterations in vascular sympathetic control. J Physiol 587:2049-2057

57. Ec Hart, Bg Wallin, Tb Curry, Mj Joyner, Karlsson T, Charkoudian N (2011) Hysteresis In The Sympathetic Baroreflex: role Of Baseline Nerve Activity. J Physiol 589:3395-3404

58. Grassi G, Seravalle G, Brambilla G, Pini C, Alimento M, Facchetti R, Spaziani D, Cuspidi C, Mancia G (2014) Marked sympathetic activation and baroreflex dysfunction in true resistant hypertension. Int J Cardiol 177:1020-1025

59. Seravalle G, Quarti-Trevano F, Dell'oro R, Gronda E, Spaziani D, Facchetti R, Cuspidi C, Mancia G, Grassi G (2019) Sympathetic and baroreflex alterations in congestive heart failure with preserved, midrange and reduced ejection fraction. J Hypertens 37:443-448

60. Dell'oro R, Gronda E, Seravalle G, Costantino G, Alberti L, Baronio B, Staine T, Vanoli E, Mancia G, Grassi G (2017) Restoration of normal sympathetic neural function in heart failure following baroreflex activation therapy: final 43-month study report. J Hypertens 35:2532-2536

Publisher's Note Springer Nature remains neutral with regard to jurisdictional claims in published maps and institutional affiliations. 